\title{
Postoperative adjuvant TACE for patients of hepatocellular carcinoma in AJCC stage I: friend or foe? a propensity score analysis
}

\author{
Yifan Tong ${ }^{1}$, Zheyong Li ${ }^{2}$, Yuelong Liang ${ }^{2}$, Hong Yu' ${ }^{2}$, Xiao Liang ${ }^{2}$, Hui Liu ${ }^{3}$, Xiujun Cai ${ }^{2}$ \\ ${ }^{1}$ Medical College of Zhejiang University, Hangzhou, China \\ ${ }^{2}$ Department of General Surgery, Sir Run Run Shaw Hospital Affiliated to Medical College of Zhejiang University, Hangzhou, China \\ ${ }^{3}$ Department of Biological Treatment Research Center, Sir Run Run Shaw Hospital Affiliated to Medical College of Zhejiang \\ University, Hangzhou, China
}

Correspondence to: Xiujun Cai, email: caixiujunzju@163.com

Keywords: TACE, overall survival, disease-free survival, hepatocellular carcinoma, AFP

Received: January 09, $2017 \quad$ Accepted: February 17, $2017 \quad$ Published: March 01, 2017

Copyright: Tong et al. This is an open-access article distributed under the terms of the Creative Commons Attribution License (CC-BY), which permits unrestricted use, distribution, and reproduction in any medium, provided the original author and source are credited.

\section{ABSTRACT}

Background: Although the transcatheter arterial chemoembolization (TACE) was demonstrated to be an alternative treatment of hepatocellular carcinoma with favorable oncological effect, the benefit of postoperative adjuvant TACE was still controversial. The aim of this study was to evaluate the effect of postoperative TACE in hepatocellular carcinoma.

Results: The 1, 3, and 5-year overall and disease-free survival rates were comparable between Surgery+TACE and Surgery groups. In subgroup analysis, tumor size $(\geq 5 \mathrm{~cm})$ was detrimental to disease-free survival $(p=0.028)$ and an inferior tendency of overall survival was presented. Besides, repeated TACE for patients contributed to a poor disease-free survival $(p=0.005)$. While, postoperative adjuvant TACE improved the overall survival in patients with high preoperative alphafetoprotein or positive pathologically $(p=0.039$ and $p=0.045)$.

Materials and Methods: The data were collected from consecutive patients between January 2010 and September 2014. After propensity score matching, baseline characteristics, overall and disease-free survival were compared between two groups. Subsequently, univariate and subgroup analysis were carried on.

Conclusions: Our study indicated that single postoperative adjuvant TACE was beneficial for selected patients of stage I with tumor less than $5 \mathrm{~cm}$, or high preoperative alpha-fetoprotein in serum or positive of alpha-fetoprotein pathologically.

\section{INTRODUCTION}

Hepatocellular carcinoma (HCC) is the fifth common cancer and the third leading cause of cancer-related death worldwide. [1] Merely 20\% patients diagnosed as HCC are applicable for operation, and transcatheter arterial chemoembolization (TACE) is the refenrenced treatment for patients with unresectable tumor. [2-5] Theoretically, TACE is not only inducing the hypoxia and necrosis of tumor by embolism of feeding artery, but also suppressing tumor activity through chemotherapy. $[6,7]$

While, it is worrying that postoperative TACE, as an adjuvant therapy, brings down therapeutic effect due to the removal of tumor previously. Meanwhile, postoperative TACE increases the adverse events. In some medical centers, especially in Asia, postoperative adjuvant TACE was recommended experientially for patients with adverse prognostic factors (e.g. thrombus of portal vein, microvascular invasion, multiple lesions). However, only few of studies with respect to postoperative adjuvant TACE in the treatment of HCC in American Joint Committee On Cancer (AJCC) stage I, were published, [8-11]. Therefor, the postoperative adjuvant TACE, as a friend or foe, needs to be explored in the comprehensive treatment of HCC in AJCC stage I.

Although the randomized controlled trial is the ideal method to elucidate the benefits and drawbacks of postoperative adjuvant TACE, it is difficult to recruit enough patients to analyze the survival rates. Under such a circumstance, retrospective study based on propensity 
score matching minimized the selection bias to increase the level of evidence. The aim of this study was to analyze retrospectively whether the postoperative adjuvant TACE was beneficial or not for patients of HCC in AJCC Stage I.

\section{RESULTS}

Each group contained 83 patients. Although some original baseline characteristics presented the heterogeneity (Supplementary Table 1), all demographic characteristics of two groups shown in Table 1 were comparable after propensity score matching. Table 2 compared the surgical and pathological outcomes of two groups, which presented similar results without significant difference. 37 out of 83 patients in Surgery+TACE group underwent selected TACE. Besides, 19 (22.9\%) patients with 27 adverse events occurred totally, and all patients above-mentioned recovered smoothly with symptomatic treatments.

For long-term outcomes, the mean time of follow-up were 37.6 months in Surgery group and 31.5 months in Surgery+TACE group. The 1, 3 and 5-year overall survival rates were $97.6 \%, 84.8 \%$, and $78.2 \%$, respectively, in the Surgery group, and $100 \%, 91.5 \%$, and $83.3 \%$, respectively, in the Surgery+TACE group $(p=0.995)$. The 1,3 and $5-$ year disease-free survival rates were $90.4 \%, 64.3 \%$, and $51.6 \%$, respectively, in the Surgery group, and $87.5 \%$, $56.4 \%$, and $50.0 \%$, respectively, in the Surgery+TACE group ( $p=0.297)$ (Figure 1).

Subsequently, univariate analysis indicated that satellite focus and rupture of tumor were shown as negative factors for overall and disease-free survival (Supplementary Figure 1). While tumor size $(\geq 5 \mathrm{~cm}$ ) was an independent adverse factor for disease-free survival with hazard ratio of $1.73(p=0.013)$. Besides, not only detrimental effect was shown in disease-free survival $(p=0.028)$, an inferior tendency of overall survival among the patients with large tumor size $(\geq 5 \mathrm{~cm})$ was presented although without significant difference (Figure 2).

In subgroup analysis, patients of Surgery+TACE group started to receive TACE from half a month to eight months after liver resection (two patients delayed the TACE procedure in six and eight months as personal reasons), and the mean of times of TACE was 1.3 \pm 0.6 times. With respect to the timing of adjuvant TACE (the boundary was 60-day after operation), earlier TACE did not improve the prognosis. Furthermore, repeated TACE for patients was detrimental to disease-free survival $(p=0.005)$ (Supplementary Figure 2). Compared with patients underwent non-selected TACE, selected TACE group presented a better tendency of overall survival but without significant difference, while the disease-free survival seemed paralleled (Supplementary Figure 3). And the adverse events of two groups were similar.

Notwithstanding, the AFP did not display the correlation with prognosis in univariate analysis before, it was yet demonstrated to have an impact on survival. For patients with high preoperative AFP $(\geq 200 \mathrm{ng} / \mathrm{mL})$ in peripheral serum, postoperative TACE improved the overall survival ( $p=0.039$ ) (Figure 3$)$. On the contrary, in patients with low peripheral AFP $(<200 \mathrm{ng} / \mathrm{mL})$ before operation, both the overall and disease-free survival of groups were comparable (Supplementary Figure 4). In terms of expression of AFP in the specimen, $44(26.5 \%)$ patients were positive, $68(41.0 \%)$ were negative, and $54(32.5 \%)$ were undetected. According to the analysis of survival, AFP positive of immunohistochemistry was also the indication of postoperative TACE (Figure 4) (Supplementary Figure 4).

\section{DISCUSSION}

Globally, TACE was the preferential treatment for unresectable $\mathrm{HCC}$ and an alternative treatment for small or intermediate HCC with favorable outcomes, although the adverse effects, extra cost, lack of high-level evidence to support the benefit of prognosis from postoperative TACE, limited its application in clinical. [12-20] For the adjuvant TACE, the absence of tumor contributed to a complicated influence by changing the micro-environment of tumor, although the concentration of chemotherapy drugs were increased through the embolism. The hypoxia effect caused by TACE procedure, also led to the ischemia of tumor-free hepatocytes, stimulating the expression of vascular endothelial growth factor (VEGF) and activation of related signaling pathways, which induced the neoangiogenesis and formed tumor favorite microenvironment. [12,21-24] Besides residual tumor cell became aggressive though up-regulation of the VEGF, the susceptibility to chemotherapy declined as the expression of drug-resistant genes increased on hypoxia stress, which might be partial responsible for the negative impact on prognosis.

In the present study, both the overall and disease-free survival of Surgery+TACE and Surgery group were comparable. According to prognostic analysis with cox regression, tumor size, satellite focus, and rupture of tumor were adverse prognostic factors. To speak of patients with satellite focus or rupture of tumor, the small sample size of positive cases restricted a further analysis. As tumor size was confirmed to be relevant to disease-free survival, large tumor was apt to s necrosis and releasing VEGF especially in the center area. A Possible hypothesis was that postoperative adjuvant TACE triggered the proliferation and activity of residual cancer cells, which overrode the anti-tumor effect under the condition of hypoxia. Definitely, the mechanism remained vague and should be illustrated in detail.

Furthermore, molecular markers might be potential value of application in prediction and treatment of malignancies. In subgroup analysis, AFP before operation in peripheral serum as well as expression of AFP with 
Table 1: Demographic characteristics

\begin{tabular}{|c|c|c|c|}
\hline & $\begin{array}{l}\text { Surgery Group } \\
\quad(n=83)\end{array}$ & $\begin{array}{c}\text { Surgery+TACE Group } \\
(n=83)\end{array}$ & $P$-value \\
\hline Age (years) & $61.0(36-83)$ & $57.0(34-83)$ & 0.121 \\
\hline Gender (Male) & $71(85.5 \%)$ & $72(86.7 \%)$ & 0.822 \\
\hline BMI $\left(\mathrm{kg} / \mathrm{m}^{2}\right)$ & $23.9(17.5-31.6)$ & $24.1(16.2-32.2)$ & 0.612 \\
\hline Serum HBV & $64(77.1 \%)$ & $70(84.3 \%)$ & 0.157 \\
\hline Serum HCV & $1(1.2 \%)$ & $0(0 \%)$ & 1.000 \\
\hline Hemoglobin $(\mathrm{g} / \mathrm{L})$ & $14.0(8.0-17.1)$ & $14.3(8.9-17.1)$ & 0.125 \\
\hline $\operatorname{ALT}(\mathrm{IU} / \mathrm{L})$ & $38.0(7.0-128.0)$ & $36.0(13.0-186.0)$ & 0.092 \\
\hline Prothrombin Time (s) & $13.4(11.5-17.3)$ & $13.5(11.7-23.0)$ & 0.696 \\
\hline Albumin $(\mathrm{g} / \mathrm{L})$ & $40.5(28.2-51.0)$ & $41.8(23.4-50.6)$ & 0.298 \\
\hline Total Bilirubin $(\mu \mathrm{mol} / \mathrm{L})$ & $15.5(3.2-50.7)$ & $14.8(3.4-47.9)$ & 0.451 \\
\hline Alpha-fetoprotein (ng/mL) & $14.7(1.5-11408.0)$ & $22.8(1.5-50500.0)$ & 0.743 \\
\hline Child-Pugh Grade & & & 1.000 \\
\hline A & $80(96.4 \%)$ & $81(97.6 \%)$ & \\
\hline $\mathrm{B}$ & $3(3.6 \%)$ & $2(2.4 \%)$ & \\
\hline Cirrhosis & $36(43.4 \%)$ & $35(42.2 \%)$ & 0.875 \\
\hline HBV-related & $32(38.6 \%)$ & $33(39.8 \%)$ & 0.874 \\
\hline HCV-related & $1(1.2 \%)$ & $0(0 \%)$ & 1.000 \\
\hline Schistosome & $3(3.6 \%)$ & $1(1.2 \%)$ & 0.620 \\
\hline Alcoholic & $0(0 \%)$ & $1(1.2 \%)$ & 1.000 \\
\hline Family History of HCC & $8(9.6 \%)$ & $13(15.6 \%)$ & 0.243 \\
\hline
\end{tabular}

Values are presented as median (range) or number (percentage). TACE, Transcatheter Arterial Chemoembolization; BMI, Body Mass Index; ALT, Alanine Aminotransferase; HBV, Hepatitis B virus; HCV, Hepatitis C virus; HCC, Hepatocellular Carcinoma.

immunohistochemistry confirmed, were demonstrated to be indications for postoperative adjuvant TACE. As detectable AFP reflected the activity of tumor. dual positive of AFP in plasma and tissue might improve the sensitivity and specificity, in evaluating the efficiency of postoperative adjuvant TACE theoretically. [25]

Although TACE compared with surgery, radiofrequency ablation, target therapy, supportive treatment were reported before, $[4,12,14]$ the timing and times of TACE as an adjuvant therapy remained indistinct. Too short interval time after operation increased the risk of liver damage even hepatic failure. On the other side, the cumulative rate of recurrence or metastasis would be elevated during the overlong interval time. In our study, the TACE of later group did not show any discrepancy of prognosis in comparison with early group, while repeated TACE decreased the disease-free survival. Briefly, the optimum timing of postoperative adjuvant TACE needed to be further studied and repeated TACE was not recommended. And selected TACE presented a better tendency of overall survival compared with non-selected TACE and Surgery groups. However, much effort was needed to verify the advantage of selected TACE in the reduction of side effects andnon-inferior oncological efficacy.

Several limitations of this study should be acknowledged. To begin with, potential bias could not be completely eliminated as a retrospective study. The propensity score matching was applied to reduce the selective bias as possible as we could. Additionally, the differentiation of tumor was not included in the survival analysis due to a large proportion of missing data. There was evidence that inclusion of variables with large proportion of missing data might introduce bias, though techniques handling missing values are becoming more and more sophisticated. [26] Eventually, in terms of AFP for prognosis, the synergy effect or connection inside, if existed, showed a terrific potential of application clinically. The dual positive of AFP expression in serum and tissues was more likely to improve the sensitivity and specificity in the prognostic model of survival. However, a part of patients without detecting the expression of AFP pathologically, decreased the validity of AFP on prognosis.

In conclusion, our study by propensity score matching indicated that, single adjuvant TACE after hepatectomy with negative margin was beneficial for patients of AJCC stage I with tumor less than $5 \mathrm{~cm}$, or high preoperative AFP or positive of AFP in specimen. Further investigations are definitely warranted.

\section{MATERIALS AND METHODS}

\section{Study design}

This study was approved by the Ethical Committees for Human Subjects at Sir Run Run Shaw Hospital affiliated to Zhejiang University, China. Data of 
Table 2: Short-term and pathological outcomes

\begin{tabular}{|c|c|c|c|}
\hline & $\begin{array}{l}\text { Surgery Group } \\
\quad(n=83)\end{array}$ & $\begin{array}{c}\text { Surgery+TACE Group } \\
(n=83)\end{array}$ & $P$-value \\
\hline \multicolumn{4}{|l|}{ Tumor Location } \\
\hline I & $3(3.6 \%)$ & $0(0 \%)$ & 0.245 \\
\hline II & $7(8.4 \%)$ & $6(7.2 \%)$ & 0.773 \\
\hline III & $6(7.2 \%)$ & $8(10.6 \%)$ & 0.576 \\
\hline IV & $15(18.1 \%)$ & $11(13.3 \%)$ & 0.393 \\
\hline V & $17(20.5 \%)$ & $14(16.9 \%)$ & 0.550 \\
\hline VI & $21(25.3 \%)$ & $29(34.9 \%)$ & 0.176 \\
\hline VII & $18(21.7 \%)$ & $20(24.1 \%)$ & 0.712 \\
\hline VIII & $14(16.9 \%)$ & $22(26.5 \%)$ & 0.132 \\
\hline Maximum Tumor Diameter (cm) & $3.0(0.9-11.0)$ & $3.8(0.7-11.6)$ & 0.242 \\
\hline Magnitude of Operation & & & 0.417 \\
\hline Major & $9(10.8 \%)$ & $6(7.2 \%)$ & \\
\hline Minor & $74(89.2 \%)$ & $77(92.8 \%)$ & \\
\hline \multicolumn{4}{|l|}{ Extent of resection } \\
\hline Wedge Resection & $35(42.6 \%)$ & $37(44.6 \%)$ & 0.754 \\
\hline Segmentectomy & $17(20.5 \%)$ & $12(14.5 \%)$ & 0.307 \\
\hline Left Lateral Lobectomy & $11(13.3 \%)$ & $11(13.3 \%)$ & 1.000 \\
\hline Right Posterior Lobectomy & $4(4.8 \%)$ & $6(7.2 \%)$ & 0.744 \\
\hline Anatomical Segmentectomy & $7(8.4 \%)$ & $11(13.3 \%)$ & 0.318 \\
\hline Left Hepatectomy & $3(3.6 \%)$ & $3(3.6 \%)$ & 1.000 \\
\hline Right Hepatectomy & $6(7.2 \%)$ & $3(3.6 \%)$ & 0.493 \\
\hline Satellite Focus & $1(1.2 \%)$ & $6(7.2 \%)$ & 0.122 \\
\hline Capsule & $7(8.4 \%)$ & $5(6.0 \%)$ & 0.549 \\
\hline Ruptured & $1(1.2 \%)$ & $2(2.4 \%)$ & 1.000 \\
\hline \multicolumn{4}{|l|}{ TACE } \\
\hline Selected & - & $37(44.6 \%)$ & \\
\hline Non-selected & - & $46(55.4 \%)$ & \\
\hline \multicolumn{4}{|l|}{ Adverse Events } \\
\hline Fever $\left(>38.0^{\circ} \mathrm{C}\right)$ & - & $3(3.6 \%)$ & \\
\hline Abdonimal Pain & - & $8(10.6 \%)$ & \\
\hline Nausea or Vomiting & - & $10(12.0 \%)$ & \\
\hline Thrombocytopenia $\left(<5 \times 10^{9} / \mathrm{L}\right)$ & - & $2(2.4 \%)$ & \\
\hline Leukocytopenia $\left(<1 \times 10^{9} / \mathrm{L}\right)$ & - & $4(4.8 \%)$ & \\
\hline Hepatic Failure & - & $0(0 \%)$ & \\
\hline
\end{tabular}

Values are presented as median (range) or number (percentage). TACE, Transcatheter Arterial Chemoembolization; Major resection is defined as equal or more than three segmentectomy.

consecutive patients with written informed consent, who underwent hepatectomy from January 2010 to September 2014 were collected retrospectively.

The patients with hepatocellular carcinoma in AJCC stage I confirmed pathologically were eligible for this study. The selection criteria for postoperative adjuvant TACE were good general condition, Child A or B liver function. And the patients with positive margin microscopically or palliative liver resection; transcatheter artery chemotherapy, preoperative adjuvant therapies (e.g. preoperative TACE, radiofrequency ablation, percutaneous ethanol injection, chemotherapy or sorafenib), or other postoperative adjuvant therapies expect TACE before recurrence and metastasis during the period of follow-up, were excluded.

Patients enrolled who underwent surgery followed by adjuvant TACE were defined as Surgery+TACE group, while who underwent hepatectomy alone without adjuvant treatment were defined as Surgery group. From 115 patients of Surgery+TACE group and 91 patients of Surgery group, 83 pairs were matched by propensity score analysis. Demographic characteristics, surgical and pathological outcomes, and long-term outcomes including overall survival and disease-free survival, were compared between two groups. 
Overall Survival

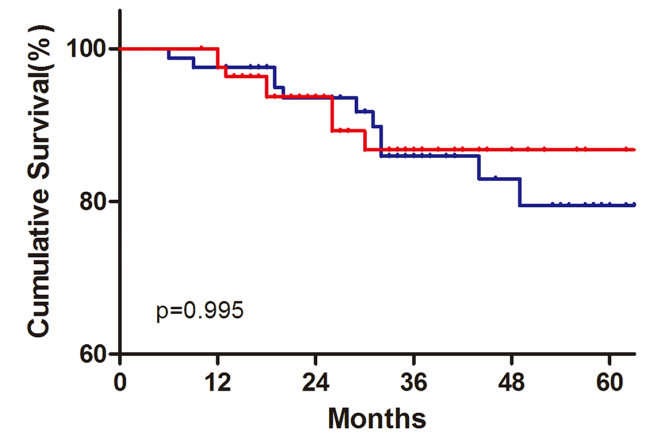

Disease-free Survival

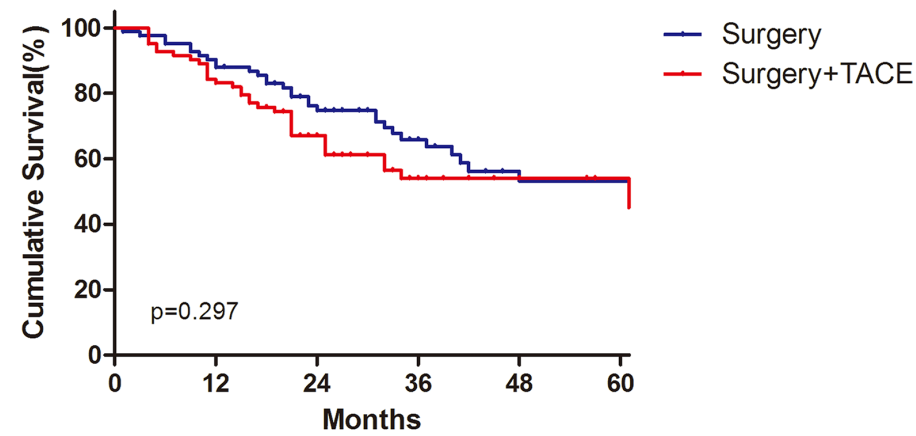

No. of Patients at risk

$\begin{array}{ccccccc}\text { Year } & 0 & 1 & 2 & 3 & 4 & 5 \\ \text { Suregry } & 83 & 75 & 52 & 32 & 19 & 11 \\ \text { Surgery+TACE } & 83 & 70 & 38 & 21 & 10 & 4\end{array}$

Figure 1: Overall and disease-free survival. Overall survival (Left) and Disease-free survival (Right). TACE, Transcatheter Arterial chemoembolization.
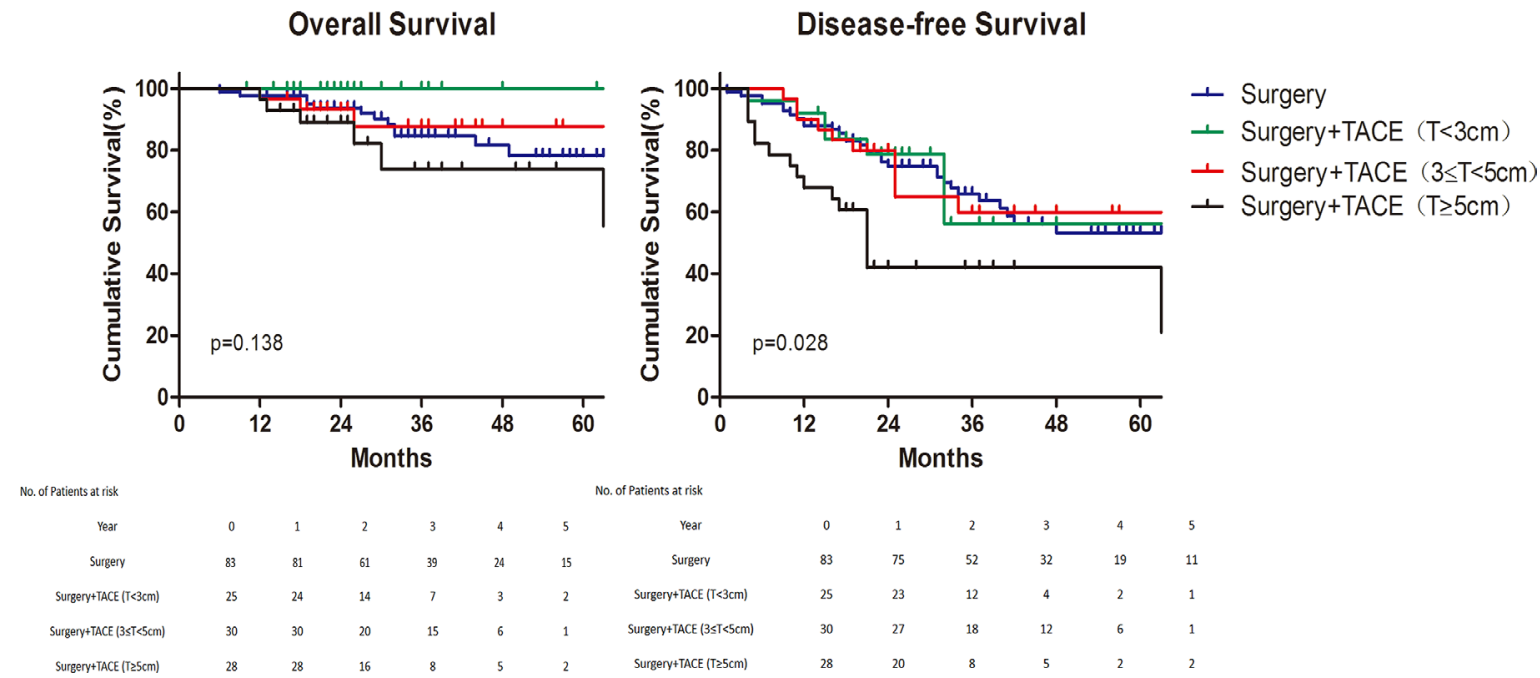

Figure 2: Subgroup analysis of survival for different tumor size. Overall survival (Left) and Disease-free survival (Right). TACE, Transcatheter Arterial chemoembolization.

Overall Survival
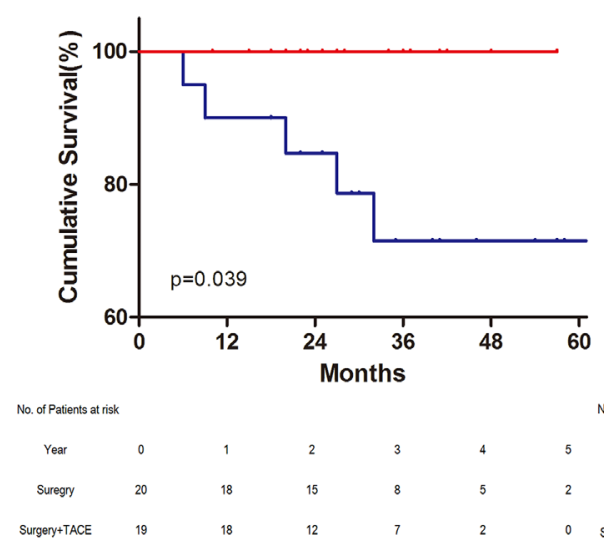

Disease-free Survival

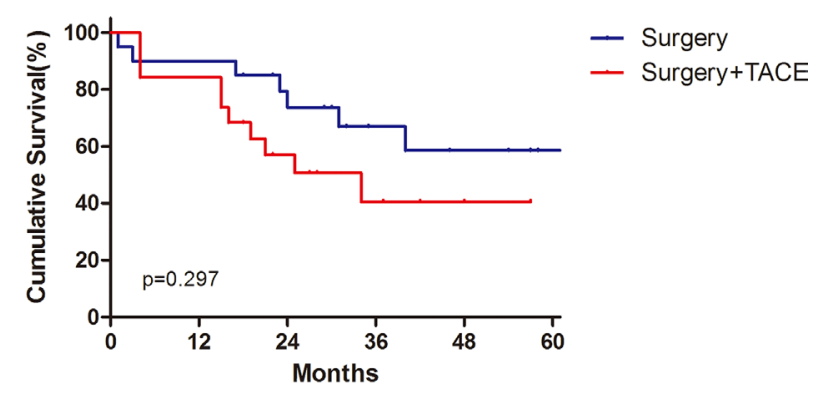

No. of Patients at risk

Year $\quad 0$

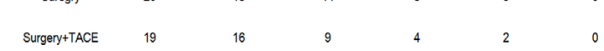

Figure 3: Survival for patients with preoperative alpha-fetoprotein $\geq \mathbf{2 0 0} \mathbf{n g} / \mathbf{m L}$. Overall survival (Left) and Disease-free survival (Right). TACE, Transcatheter Arterial chemoembolization. 


\section{TACE procedure and follow-up}

All patients underwent TACE procedure by experienced interventional radiologists of same team. The 5-F French catheter was access to the aorta abdominalis through superficial femoral artery with the seldinger technique, followed by hepatic arterial angiography with guidance of Yashiro catheter. As all patients underwent hepatectomy, appropriate arteries or branches were targeted according to the different extent of resection. Selected TACE was defined as targeted to the segment of artery. Generally, a mixture of mitomycin $10 \mathrm{mg}$, epirubicin $50 \mathrm{mg}$ and lipiodol $10 \mathrm{ml}$ was injected, simultaneously, oxaliplatin $150 \mathrm{mg}$ was perfused intermittently, followed by embolism with spongel particles until blood flow almost stopped. Fluidsupplement therapy was performed routinely, and liver protection drugs or antibiotics were supplied, if necessary.

A standardized follow-up protocol was adopted for all the patients. During the follow-up, in addition to a detailed history taking and physical examination, the patients received ultrasound of the abdomen, serum AFP, blood routine and liver function. Abdominal Computed Tomography or Magnetic Resonance Imaging were performed when clinically indicated. Patients in Surgery+TACE group underwent first TACE were required in 15 to 90 days after operation generally. If AFP in peripheral serum was elevated, or suspicious lesion on imaging examination, or iodized oil accumulation, the repeated TACE procedure was performed. All patients of both groups were regularly followed up every 3 to 6 months until the fifth year. Later, follow-up annually was carried on.

\section{Statistical analysis}

The continuous variables were expressed as median with range and categorical data were presented as number with proportion. Correspondingly, the Mann-Whitney $U$ test was used to compare continuous variables, while the Chi-square test or Fisher exact test, was used to compare categorical variables as appropriate. Cumulative survival was presented as Kaplan-Meier curves and compared by the log-rank test. Overall and disease-free survival were analyzed with univariate cox regression model. The propensity score matching was applied to eliminate bias of selection.

According to the baseline characteristics, including age, gender, body mass index (BMI), Child-Pugh grade, cirrhosis and tumor size, two groups were paired with ratio of one-to-one nearest neighbor matching estimated propensity score within 0.1 of caliper width (Figure 5).
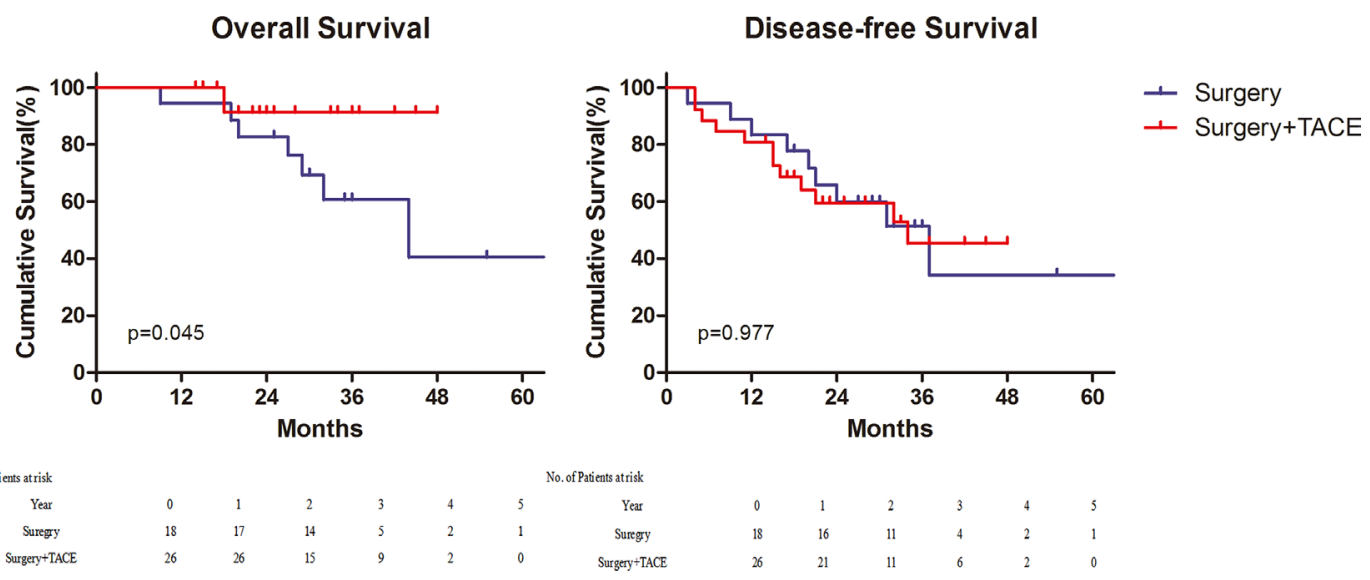

Figure 4: Survival for patients with immunohistochemical alpha-fetoprotein positive. Overall survival (Left) and Disease-free survival (Right). TACE, Transcatheter Arterial chemoembolization.

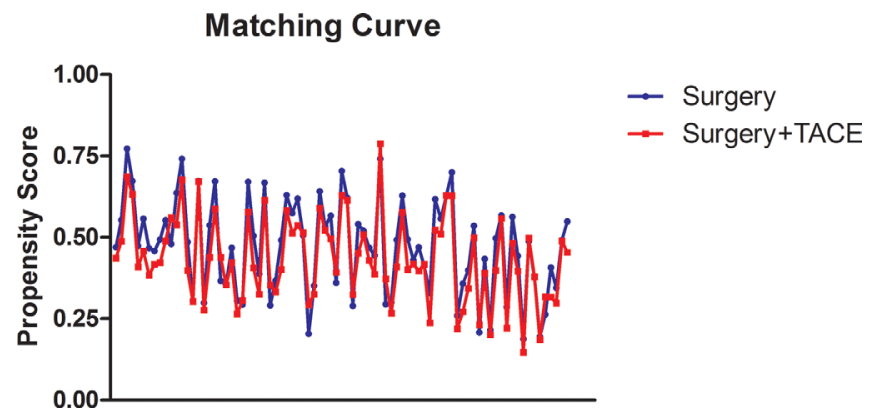

Figure 5: Propensity matching curve. TACE, Transcatheter Arterial chemoembolization. 
The $p$-value with two-tailed less than 0.05 was defined as significant difference. Statistical analysis was performed using SPSS, version 22.0 for Windows (IBM Corporation, Armonk, NY).

\section{Abbreviations}

AFP: Alpha-fetoprotein; AJCC: American Joint Committee on Cancer; DFS: Disease-free Survival; HCC: Hepatocellular Carcinoma; OS: Overall Survival; TACE: Transcatheter Arterial chemoembolization; VEGF: Vascular Endothelial Growth Factor

\section{ACKNOWLEDGMENTS}

Thanks for support by the Independent Scientific Research Projects of Zhejiang Universities (No. 2016FZA7004).

\section{CONFLICTS OF INTEREST}

The authors declared no conflicts of interest was included in the study.

\section{Authors' contribution}

Study concept and design: Cai XJ, Tong YF, Li ZY, Liang YL, Yu H, Liang X, Liu H; Acquisition of data: Tong YF, Li ZY, Liang YL; Statistical analysis: Liu H; Study supervision: Cai XJ, Tong YF, Yu H, Liang X

\section{REFERENCES}

1. Jemal A, Bray F, Center MM, Ferlay J, Ward E, Forman D. Global cancer statistics. CA Cancer J Clin. 2011;61:69-90.

2. Sieghart W, Hucke F, Peck-Radosavljevic M. Transarterial chemoembolization: modalities, indication, and patient selection. J Hepatol. 2015; 62:1187-95.

3. Zhu K, Chen J, Lai L, Meng X, Zhou B, Huang W, Cai M, Shan H. Hepatocellular carcinoma with portal vein tumor thrombus: treatment with transarterial chemoembolization combined with sorafenib - a retrospective controlled study. Radiology. 2014; 272:284-93.

4. Llovet JM, Real MI, Montaña X, Planas R, Coll S, Aponte J, Ayuso C, Sala M, Muchart J, Solà R, Rodés J, Bruix J; Barcelona Liver Cancer Group. Arterial embolisation or chemoembolisation versus symptomatic treatment in patients with unresectable hepatocellular carcinoma: a randomised controlled trial. Lancet. 2002; 359:1734-9.

5. Lo CM, Ngan H, Tso WK, Liu CL, Lam CM, Poon RT, Fan ST, Wong J. Randomized controlled trial of transarterial lipiodol chemoembolization for unresectable hepatocellular carcinoma. Hepatology. 2002; 35:1164-71.
6. Chen C, Wang J, Liu R, Qian S. RNA interference of hypoxia-inducible factor-1 alpha improves the effects of transcatheter arterial embolization in rat liver tumors. Tumour Biol. 2012; 33:1095-103.

7. Qu K, Yan Z, Wu Y, Chen Y, Qu P, Xu X, Yuan P, Huang X, Xing J, Zhang H, Liu C, Zhang J. Transarterial chemoembolization aggravated peritumoral fibrosis via hypoxia-inducible factor-1 $\alpha$ dependent pathway in hepatocellular carcinoma. J Gastroenterol Hepatol. 2015; 30:925-32.

8. Cheng CH, Lee CF, Wu TH, Chan KM, Chou HS, Wu TJ, $\mathrm{Yu}$ MC, Chen TC, Lee WC, Chen MF. Evaluation of the new AJCC staging system for resectable hepatocellular carcinoma. World J Surg Oncol. 2011; 9:114.

9. Peña AM, Núñez-Martínez Ó, Díaz-Sánchez A, PonsRenedo F, Gómez-Rubio M, Polo-Lorduy B, LledóNavarro JL, Trapero-Marugán M, Ladero-Quesada JM, Poves-Martínez E, Ibáñez-Pinto A, Martín-Algívez AM, Lozano-Maya M, et al. Transarterial chemoembolisation in intermediate-stage hepatocellular carcinoma. Survey on clinical practice in hospitals in the Madrid Region. Ann Hepatol. 2015; 14:207-17.

10. Raoul JL, Sangro B, Forner A, Mazzaferro V, Piscaglia F, Bolondi L, Lencioni R. Evolving strategies for the management of intermediate-stage hepatocellular carcinoma: available evidence and expert opinion on the use of transarterial chemoembolization. Cancer Treat Rev. 2011; 37:212-20.

11. Meng MB, Cui YL, Lu Y, She B, Chen Y, Guan YS, Zhang RM. Transcatheter arterial chemoembolization in combination with radiotherapy for unresectable hepatocellular carcinoma: a systematic review and metaanalysis. Radiother Oncol. 2009; 92:184-94.

12. Yin $\mathrm{X}$, Zhang L, Wang $\mathrm{YH}$, Zhang BH, Gan YH, Ge NL, Chen Y, Li LX, Ren ZG. Transcatheter arterial chemoembolization combined with radiofrequency ablation delays tumor progression and prolongs overall survival in patients with intermediate (BCLC B) hepatocellular carcinoma. BMC Cancer. 2014; 14:849.

13. Song DS, Nam SW, Bae SH, Kim JD, Jang JW, Song MJ, Lee SW, Kim HY1, Lee YJ, Chun HJ, You YK, Choi JY, Yoon SK. Outcome of transarterial chemoembolizationbased multi-modal treatment in patients with unresectable hepatocellular carcinoma. World J Gastroenterol. 2015; 21:2395-404.

14. Pinter M, Hucke F, Graziadei I, Vogel W, Maieron A, Königsberg R, Stauber R, Grünberger B, Müller C, Kölblinger C, Peck-Radosavljevic M, Sieghart W. Advanced-stage hepatocellular carcinoma: transarterial chemoembolization versus sorafenib. Radiology. 2012; 263:590-9.

15. Yeh ML, Huang CI, Huang CF, Hsieh MY, Huang JF, Dai CY, Lin ZY, Chen SC, Yu ML, Chuang WL. 
Neoadjuvant transcatheter arterial chemoembolization does not provide survival benefit compared to curative therapy alone in single hepatocellular carcinoma. Kaohsiung J Med Sci. 2015; 31:77-82.

16. Cohen MJ, Bloom AI, Barak O, Klimov A, Nesher T, Shouval D, Levi I, Shibolet O. Trans-arterial chemoembolization is safe and effective for very elderly patients with hepatocellular carcinoma. World J Gastroenterol. 2013; 19:2521-8.

17. Zhong JH, Xiang BD, Gong WF, Ke Y, Mo QG, Ma L, Liu X, Li LQ. Comparison of long-term survival of patients with BCLC stage B hepatocellular carcinoma after liver resection or transarterial chemoembolization. PLoS One. 2013; 8:e68193.

18. Takuma Y, Takabatake H, Morimoto Y, Toshikuni N, Kayahara T, Makino Y, Yamamoto H. Comparison of combined transcatheter arterial chemoembolization and radiofrequency ablation with surgical resection by using propensity score matching in patients with hepatocellular carcinoma within Milan criteria. Radiology. 2013; 269:927-37.

19. Wu KT, Wang CC, Lu LG, Zhang WD, Zhang FJ, Shi F, Li CX. Hepatocellular carcinoma: clinical study of longterm survival and choice of treatment modalities. World J Gastroenterol. 2013; 19:3649-57.

20. Liu H, Zhang A, Qian N, Gao L, Xu L, Zhang W, Jiang K, Cai S, Huang Z, Dong J. Postoperative transarterial chemoembolization benefits patients with high $\gamma$ glutamyl transferase levels after curative hepatectomy for hepatocellular carcinoma: a survival stratification analysis. Tohoku J Exp Med. 2012; 227:269-80.
21. Li X, Feng GS, Zheng CS, Zhuo CK, Liu X. Expression of plasma vascular endothelial growth factor in patients with hepatocellular carcinoma and effect of transcatheter arterial chemoembolization therapy on plasma vascular endothelial growth factor level. World J Gastroenterol. 2004; 10:2878-82.

22. Lin TY, Chou CF, Chung HY, Chiang CY, Li CH, Wu JL, Lin HJ, Pai TW, Hu CH, Tzou WS. Hypoxia-inducible factor 2 alpha is essential for hepatic outgrowth and functions via the regulation of leg1 transcription in the zebrafish embryo. PLoS One. 2014; 9:e101980.

23. Bouquerel P, Gstalder C, Müller D, Laurent J, Brizuela L, Sabbadini RA, Malavaud B, Pyronnet S, Martineau Y, Ader I, Cuvillier O. Essential role for SphK1/S1P signaling to regulate hypoxia-inducible factor $2 \alpha$ expression and activity in cancer. Oncogenesis. 2016; 5:e209.

24. Ader I, Brizuela L, Bouquerel P, Malavaud B, Cuvillier O. Sphingosine kinase 1: a new modulator of hypoxia inducible factor 1alpha during hypoxia in human cancer cells. Cancer Res. 2008; 68:8635-42.

25. Eltawil KM, Berry R, Abdolell M, Molinari M. Analysis of survival predictors in a prospective cohort of patients undergoing transarterial chemoembolization for hepatocellular carcinoma in a single Canadian centre. HPB (Oxford). 2012; 14:162-70.

26. Zhang Z. Missing values in big data research: some basic skills. Ann Transl Med. 2015; 3:323. 